\title{
The Comparatıve Evaluation of Fine Needle Aspiration Biopsy Results of the Cases Which Are Atypia of Undetermined Significance and the Surgical Material Results
}

\author{
Tiroid İnce İğne Aspirasyon Biyopsi Sonucu Önemi Belirsiz Atipi \\ Olan Olguların Ameliyat Materyalleri Sonuçları ile Karșılaștırmalı \\ Değerlendirilmesi
}

\author{
Hüseyin Eken ${ }^{1}$, Eray Kurnaz ${ }^{2}$, Mecdi Gürhan Balcl ${ }^{3}$, Mithat Kerim Arslan² \\ 'Erzincan Üniversitesi Tıp Fakültesi, Genel Cerrahi Anabilim Dalı, Erzincan, Türkiye \\ ${ }^{2}$ Binali Yıldırım Üniversitesi Mengücek Gazi Eğitim ve Araştırma Hastanesi, Genel Cerrahi Kliniği, Erzincan, Türkiye \\ ${ }^{3}$ Erzincan Üniversitesi Tıp Fakültesi, Patoloji Anabilim Dalı, Erzincan, Türkiye
}

ÖZ

Tiroid nodüllerinin prevelansı oldukça yüksektir. Bu nodüllerden malignite gelișme oranı ve tiroid kanserlerindeki mortalite oranı düșüktür. Tedavi seçimi ve hastaların takibi açısından malign nodüller ile benign nodüller arasında ayrım yapılması oldukça önemlidir. Ultrasound eșliğinde ince iğne aspirasyon biyopsisi (iïAB) yapılması tiroid nodüllerinin değerlendirilmesi için en uygun yöntemdir. Çalıșmanın amacı IİAB sonucu önemi belirsiz atipi olan hastaların ameliyat sonrası patoloji sonuçlarının iïAB sonuçcları ile karșılaștırmalı olarak değerlendirilmesi, sonuçları literatürle paylașarak hastaların tedavi ve takibine katkı sağlamaktır. Çalıșmada 2013-2018 yılları arasında tiroid IïAB yapılan 3148 hasta değerlendirildi. IİAB sonucu önemi belirsiz atipi olan ve radyolojik olarak en az iki malign șüpheli görünümü olan hastalara veya 3-6 ay sonra yapılan ikinci IïAB sonucu tekrar önemi belirsiz atipi gelen hastalara cerrahi tedavi uygulandı. IİAB sonuçları ve ameliyat sonrası tanıları karșılaștırılarak incelendi. ï̇AB sonuçları önemi belirsiz atipi olarak raporlanan 134 hasta mevcuttu. Histopatolojik inceleme sonrası 9 hastada (\%23,1) malignite saptandı. Sitoloji sonucu önemi belirsiz atipi gelen ve radyolojik olarak malignite kriterleri taşıyan hastalarda cerrahi planlamanın doğru yaklaşım olacağı ve hastaların takip zorluğundan kaynaklanan tanısal gecikmeleri engelleyeceğini düşünmekteyiz.

\section{ABSTRACT}

The prevalence of thyroid nodules is absolutely high. The incidence of malignancy development from that nodules and the mortality in thyroid cancers are low. It is very important to distinguish between malignant nodules and benign nodules because of the choice of treatment and follow-up of patients. Ultrasound-guided fine needle aspiration biopsy (FNAB) is the most appropriate method for the evaluation of thyroid nodules. The aim of the study is to evaluate the postoperative pathology results of patients with atypia of undetermined significance with FNAB results, to share the results with the literature and to contribute to the treatment and follow-up of patients. The study included 3148 patients who underwent thyroid FNAB between the years of 2013-2018. The patients who had atypia of undetermined significance of FNAB results and who had at least two radiological malignant suspicious appearance, or the second FNAB performed after 3 months was reported as atypia of undetermined significance, were treated with thyroidectomy. FNAB results and postoperative diagnosis were comparatively examined. It was reported that 134 patients with an atypia of undetermined significance of FNAB results. Malignancy was detected in 9 patients (6.7\%) after histopathological examination. We conclude that surgical planning will be the correct approach in patients with atypia of undetermined significance and in patients who have radiological malignancy criteria to prevent diagnostic delays due to follow-up difficulties.

Received / Geliș tarihi: 16.10.2018 | Accepted / Kabul tarihi: 12.01 .2019

Address for Correspondence / Yazıșma Adresi: Hüseyin Eken, Erzincan Üniversitesi Tıp Fakültesi, Genel Cerrahi Anabilim Dalı, Erzincan, Türkiye Phone / Telefon: +90 5052571379 E-mail / E-posta: huseyineken80@hotmail.com ORCID-ID: orcid.org/0000-0001-6095-6002

Citation / Atıf: Monur M, Avci A, Satar S. Evaluation of patients admitted to pediatric emergency service by 112 ambulance. Bakırköy Tip Dergisi 2018;14:253-62. https://doi.org/10.5350/BTDMJB.20160930125348 


\section{GiRiș}

Tiroid nodüllerinin prevelansı oldukça yüksek olmasına rağmen bu nodüllerden malignite gelişme oranı ve diğer organ maligniteleri ile karşılaştırıldığında tiroid kanserlerindeki mortalite oranı düşüktür. En yaygın endokrin malignite olan tiroid kanserlerinde on yıllıkyaşam beklentisi \% 90 - \% 95 düzeylerindedir. Tiroid kanserlerinin yaklașık \% 90'ı papiller karsinomdur. Cerrahi veya medikal tedavi seçimi ve hastaların takibi açısından malign nodüller ile benign nodüller arasında ayrım yapılması oldukça önemlidir. Ultrasonografi ve ultrasonografi eșliğinde ince iğne aspirasyon biyopsisi (iiAB) yapılması tiroid nodüllerinin değerlendirilmesi için en uygun yöntemdir (1). Kliniğimizde büyüklüğü $1 \mathrm{~cm}$ üzerinde olan nodüllere iiAB yapılmaktadır. Amerikan Ulusal Kanser Enstitüsü tarafından tiroid nodüllerini kategorize etmek amacıyla Bethesda Sınıflandırma Sistemi yayınlanmıştır ( Tablo 1 ).

Bu sınıflandırmaya göre tiroid nodülleri; nondiagnostik, benign, önemi belirsiz atipi veya önemi belirsiz folliküler lezyon, folliküler neoplazi veya folliküler neoplazi şüphesi, malinite șüpheli ve malign olarak gruplandırılmaktadır. Önemi belirsiz atipi kategorisi yapısal ve/veya nükleer atipi içeren, ancak foliküler neoplazi açısından șüpheli, malignite açısından şüpheli yada malign olarak sınıflandırılamayan hücrelerden oluşan örnekler için kullanılmaktadır (2).

Bu sistem ayrıca her kategori için muhtemel malignite oranlarını ve uygun tedavi seçeneklerini de bildirmektedir (2). Bethesda sistemi bu olgularda \%5 - \%15 oranında malignite riski olduğunu öngörmektedir (3). iïAB yapılan nodüllerde yaklaşık \% 20 oranında önemi belirsiz atipi görülmektedir (4). Yapılan çalışmalarda IİAB sonucu önemi belirsiz atipi olan hastaların ameliyat materyallerinin histopatolojik incelenmesi sonucu \%6 - \%96,7 oranında maligniteye rastlandığı bildirilmektedir $(5,6)$.

Çalışmanın amacı IİAB sonucu önemi belirsiz atipi (Bethesda kategori 3) olarak raporlanan hastaların ameliyat materyallerindeki patoloji sonuçlarının ii $A B$

Tablo 1. 2017 Bethesda Tiroid Sitopatolojisi Raporlama Sistemi (11)

\begin{tabular}{ll}
\hline I & Nondiagnostik \\
II & Benign \\
III & Önemi Belirsiz Atipi veya Önemi Belirsiz Folliküler Lezyon \\
IV & Folliküler Neoplazi veya Folliküler Neoplazi Şüpheli \\
V & Malignite Şüpheli \\
VI & Malign \\
\hline
\end{tabular}

sonuçları ile karşılaştırmalı olarak değerlendirilmesi, sonuçları literatürle paylaşarak hastaların tedavi ve takibine katkı sağlamaktır.

\section{GEREÇ ve YÖNTEMLER}

Çalışmaya 2013-2018 yılları arasında, klinik muayene ve ultrasonografik değerlendirme sonucu tiroid nodülü saptanan ve bu nodüllere IIAB yapılan 3148 olgu dahil edildi. Hastaların yașı, cinsiyeti, nodül boyutu ve lokalizasyonu, ultrasonografi bulguları preoperatif klinik veriler olarak kayıt edildi. TSH ve T4 değerleri ölçüldü, tiroid ultrasonografisi sonuçları değerlendirildi. Ultrasonografi sonuçlarında nodüllerde düzensiz sınırlar, mikrokalsifikasyon ve internal vaskülarizasyon görülmesi malignite șüpheli radyolojik bulgular olarak kabul edildi.

iïB uygulanan hastaların sitolojik spesmenlerinin tamamı takibe alındı. Materyallerin bir kısmı lamlara yayılarak alkolle fiske edildikten sonra, bir kısmı ise lamlara yayılarak havada kurutulduktan sonra; Hematoksilen-Eozin, Giemsa ve Papanicolaou histokimyasal boyalarla boyanarak değerlendirildi. Sitolojik değerlendirme sonrası sonuçlar Bethesda sınıflandırma kriterlerine göre değerlendirildi.

IIAB sonucu Bethesda kategori 3 olarak değerlendirilen ve radyolojik olarak en az iki malign șüpheli görünümü olan hastalara veya 3 ay sonra yapılan ikinci IïAB sonucu tekrar önemi belirsiz atipi gelen hastalara cerrahi tedavi uygulandı. Tiroidektomi materyallerindeki nodüllerden alınan örnekler patoloji laboratuarında parafin bloklara gömüldü. Parafin bloklardan alınan 4 mikronluk kesitler Hematoksilen-Eozin boyamayla boyanarak değerlendirildi. Tümör șüphesi olan vakalarda tiroid kanserlerinde tanıda immunohistokimyasal yardımcı yöntemler olan HBME-l, Galaktin 3, Cytokerarin 19, gerekli vakalarda daha geniş, immunohistokimyasal çalışma yapıldı. Hastaların IïAB sonuçları ve ameliyat sonrası tanıları karşılaștırılarak incelendi.

Çalışmada veriler basit istatistiksel yöntemle değerlendirilmiş olup sonuçlar yüzde olarak verilmiştir.

\section{BULGULAR}

IIAB sonuçları önemi belirsiz atipi olarak raporlanan 134 hasta mevcuttu. Hastaların 30-66 yaş aralığında olduğu görüldü. Ortanca yaş aralığı 48 idi . Hastaların cinsiyete göre sınıflaması yapıldığında 83 (\%61.9) hasta kadın, 51 (\%38.1) hasta erkekti. 
Cerrahi kararı almamızda etkili olan gerekçe, iïAB sonucu önemi belirsiz atipi olarak raporlanan vakalarda nodülde malignite șüphesi uyandıran iki veya daha fazla ultrasonografik bulgu olması veya 3 ay sonra yapılan ikinci IïAB sonucunun tekrar önemi belirsiz atipi gelmesi idi. Bu kriterleri taşıyan 39 hastaya total tiroidektomi yapıldı

Total tiroidektomi uygulanan 39 hastanın ameliyat materyallerinin histopatolojik incelemesi sonrası 9 hastada $(\% 23,1)$ malignite saptandı. 30 hastada $(\% 76,9)$ ise benign lezyon olduğu raporlandı. Malign hastaların 8'i $(\% 88,8)$ papiller karsinomdu. 1 hastada $(\% 11,2)$ ise tanı folliküler karsinomdu. Raporlanan benign lezyonların 18 'inde (\%60) tanı multinodüler guatr, 6'sında (\%20) Hashimoto tiroiditi, 3 'ünde (\%10) folliküler adenom, 3 'ünde (\%10) ise onkositik adenom idi.

\section{TARTIŞMA}

Tiroid nodülleri klinik, ultrasonografik ve gereklilik halinde belirli periyotlarla IIAB ile takip edilmesi gereken patolojiler olup; Bethesda Raporlama Sistemi, IIAB ile tiroid nodüllerinin sitopatolojik değerlendirilmesini standardize etmiștir. Nondiagnostik grupta IiAB tekrarı, benign grupta klinik izlem, foliküler neoplazi yada foliküler neoplazi şüphesi olan grupta cerrahi lobektomi, malignite şüpheli veya malign grupta totaleyakın tiroidektomi önerilmektedir (7). Asıl problem belli aralıklarla IïAB tekrarı önerilen kategori olan önemi belirsiz atipi/önemi belirsiz folliküler lezyon grubundadır. Bethesda Raporlama Sistemi, kategori 3 olarak değerlendirilen nodüllerde eğer șüpheli malign radyolojik görünüm yoksa 3 ay kadar sonra IIAB tekrarı önermektedir. İkinci IïAB sonucu da önemi belirsiz atipi/ önemi belirsiz folliküler lezyon olarak sonuçlanırsa cerrahi tedavi önerilmektedir (2).

Ultrasonografi sonuçlarında nodüldeki düzensiz sınırlar, mikrokalsifikasyon varlığı, hipoekojenite, internal kanlanma ve hızlı büyüme malign șüpheli radyolojik görünümler olarak kabul edilmektedir $(8,9)$. Malignite işareti olabilecek ultrasonografik özellikler temel alınarak geliștirilen TI-RADS ( Tiroid Görüntüleme Raporlama Veri Sistemi) sınıflamasında nodüller altı kategoriye ayrılmıştır. Kategori O'da tiroid bezi heterojen ekodadır fakat nodül yoktur. Kategori l'de benign nodüller, kategori 2'de muhtemel benign nodüller mevcuttur. Kategori 3'te malign şüpheli nodüller mevcut olup yukarıda bahsedilen şüpheli görünüm sayısına göre kendi içerisinde yine üç gruba ayrılır (en fazla 3 malign șüpheli görünüm içerir). Kategori 4 'te 4 ve daha fazla malignite işareti sayılabilecek özellik mevcuttur. Kategori 5 ise iïAB ile malign olduğu kanıtlanmış nodülleri içerir (10). Bir çalışmada IIAB sonucu önemi belirsiz atipi olarak bildirilen ve ultrasonografik olarak malignite șüphesi içeren iki bulgu olan hastalarda ameliyat materyallerinde kanser olarak raporlanma oranı \%66,7 olarak bildirilmiştir (11). Çalıșmamızda IIAB sonrası önemi belirsiz atipi olarak raporlanıp ultrasonografik olarak malignite șüphesi içeren iki bulgu olan ve cerrahi uygulanan 39 hastanın ameliyat materyallerinde 9 (\% 23,1) vakada malignite saptanmıştır.

Kliniğimizde IİAB sonrası önemi belirsiz atipi/önemi belirsiz folliküler lezyon olarak raporlanan nodüller multidisipliner olarak değerlendirilir. Malignite șüphesi uyandıracak radyolojik görünümü olmayan hastalara Bethesda sisteminin de önerdiği gibi IïAB tekrarı planlanır. Ultrasonografik olarak belirtilen birden çok şüpheli lezyon varlığında ise yaklașım cerrahi tedavidir (12). İlk IİAB sonucu önemi belirsiz atipi olan ve ultrasonografi bulguları ile tekrar değerlendirilerek cerrahi kararı verilen 39 hastanın tamamında (\%100) mikrokalsifikasyon mevcuttu. $24(\% 61,5)$ hastada düzensiz sınırlı nodül olduğu görüldü, $15(\% 38,4)$ hastada internal kanlanma izlendi. 27 (\%69.9) vaka IiAB raporu sonucu önemi belirsiz atipi olup en az iki ultrasonografik malignite șüphesi olan vakalardı. 12 vaka ise (\%30.1) ikinci IïAB sonucuda önemi belirsiz atipi gelen vakalardı.

IIIAB sonucu önemi belirsiz atipi gelen 134 hastanın takibinde zorluklar yaşandığı görüldü. $8(\% 6)$ hastanın takibini hiç yaptırmadığı, $32(\% 23,9)$ hastanın ise istenen sürelerden oldukça geç periyodlarla takibe geldiği saptandı. Düşük sosyoekonomik düzeye sahip bölgelerde hastaneye bașvuru oranı daha az olduğunu belirten çalıșmalar mevcuttur (13). Bu çalışmadaki hasta takibindeki aksamalarında coğrafi ve sosyoekonomik șartlardan olduğunu düșünmekteyiz. Bu durumun hasta takibini zorlaștırdığını ve takip aralıklarının fazlaca uzattığını bu nedenle patoloji raporu önemi belirsiz atipi olan ve radyolojik olarak malignite kriterleri taşıyan hastalarda cerrahi planlamanın doğru olacağını düşünmekteyiz.

\section{SONUÇ}

Tiroid IIAB yapılan, sitolojik inceleme sonrası patoloji raporu sonucu önemi belirsiz atipi olan ve radyolojik olarak malignite kriterleri taşıyan hastalarda, ameliyat 
materyallerinde oldukça yüksek sayılacak oranlarda (bizim çalıșmamızda \%23,1) kanser tanısı saptandığından, bu hastalarda cerrahi planlamanın doğru yaklaşım olacağı ve hastaların takip zorluğundan kaynaklanan tanısal gecikmeleri engelleyeceği sonucuna varıldı.

\section{KAYNAKLAR}

1. White C, Weinstein MC, Fingered AL, Randolp GW, Miyauchi A, Ito Y, Zhan T, Ali A, Gazelle GS, Lubitz CC, Is Less More? A Microsimulation Model Comparing Cost-effectiveness of the Revised American Thyroid Association's 2015 to 2009 Guidelines for the Management of Patients With Thyroid Nodules and Differentiated Thyroid Cancer.Ann surg 2018 Oct 17

2. Ali ZS, Cibas ES. The Bethesda System for Reporting Thyroid Cytopathology. New York, Springer, 2010

3. Onder S, Firat P, Ates D. The Bethesda system for reporting thyroid cytopathology: an institutional experience of the outcome of indeterminat ecategories. Cytopathology 2014;25:177-84.

4. Hamburger JI. Diagnosis of thyroid nodules by fine needle biopsy: use and abuse. J Clin Endocrinol Metab 1994;79:335-9.

5. Nayar R, Ivanovic $M$. The indeterminate thyroid fine needle aspiration: experience from an academic center using terminology similar to that proposed in the 2007 National Cancer Institute Thyroid Fine Needle Aspiration State of the Science Conference. Cancer Cytopathol. 2009; 117: 195-202
6. Kim SK, Hwang TS, Yoo YB et al. Surgical results of thyroid nodules according to a management guideline based on the BRAFV600E mutation status. J Clin Endocrinol Metab. 2011; 96: 658-64.

7. G Adaş, M Adaş, F Özülker, A Akçakaya, Tiroid Kanserleri, Okmeydanı Tıp Dergisi 28(Ek sayı 1):26-34, 2012.

8. Şafak Akın,Nafiye Helvacı, Neșe Çınar, Sevgen Önder, Miyase Bayraktar Atypia of Undetermined Significance in Thyroid FineNeedle Aspiration Cytology: Pathological Evaluation and Risk Factors for Malignancy South. Clin. Ist. Euras. 2017;28(2):82-86

9. Gharib H, Goellner JR. Fine-needle aspiration biopsy of the thyroid: an appraisal. Ann Intern Med 1993;118:282-9.

10. Xue E, Zheng $M$, Zhang S, Huang L, Qian Q, Huang $Y$, Ultrasonography - Based Classification and Reporting System for the Malignant Risk of Thyroid Nodules. J Nippon Med Sch. 2017;84(3):118-124

11. Ryu YJ, Jung YS, Yoon HC, Hwang MJ, Shin SH, Cho JS, et al. Atypia of undetermined significance on thyroid fine needle aspiration: surgical outcome and risk factors for malignancy. Ann Surg Treat Res 2014;86:109-14

12. Garcia Pascual L, Suralles ML, Marlius X, Garcia Cano L, Gonzales Minguez $C$, Prevalence and associated malignancy of Bethesda category III cytologies of thyroid nodules assigned to the "cytological atypia" or "architectural atypia" groups. Endocrinol diabetes nutr 2018 Dec;65(10):577-583. Epub 2018 Sep 24.

13. Onat A, Şenocak M, Örnek E, Şurdum-Avcı G, Öz Ö. Türk erișkinlerinde ekonomik düzeyle kanda kolesterol ilişkisi ve taramadaki örneklemin sosyal durumu. Türk Kardiyoloji Derneği Arş 1991;19: 408-12. 